\title{
Betaine Alleviates Heat Stress-Induced Hepatic and Mitochondrial Oxidative Damage in Broilers
}

\author{
Chao Wen ${ }^{1}$, Zhixian Leng ${ }^{1}$, Yueping Chen, Liren Ding, Tian Wang and Yanmin Zhou \\ College of Animal Science and Technology, Nanjing Agricultural University, Nanjing, 210095, China
}

\begin{abstract}
The aim of this study was to evaluate the effects of dietary betaine (BET) on growth performance, redox state, and related gene expression in broilers under heat stress (HS). A total of 144 21-day-old male broiler chickens with similar body weights were assigned randomly to three treatments with six replicates (eight chickens per replicate cage). Broilers in the control (CON) group were kept at thermoneutral (TN, $\left.22 \pm 1{ }^{\circ} \mathrm{C}\right)$ conditions and fed a basal diet until they were 42 days of age. Broilers in the other two groups (defined as HS and HS + BET) were exposed to HS $\left(34 \pm 1{ }^{\circ} \mathrm{C}, 8 \mathrm{~h} /\right.$ day) and fed the basal diet without or with $1000 \mathrm{mg} / \mathrm{kg}$ BET, respectively. Rectal and cockscomb temperature of broilers was increased $(P<0.05)$ in HS and HS + BET groups compared with the CON group, whereas there was no difference between HS and HS + BET groups. Dietary BET supplementation restored $(P<0.05)$ average daily gain (ADG) and average daily feed intake (ADFI) of broilers and reversed $(P<0.05)$ the increase in serum alanine transaminase (ALT) activity and malondialdehyde (MDA) content in the liver tissue of broilers under HS. The HS + BET group had higher $(P<0.05)$ activities of superoxide dismutase (SOD) and glutathione peroxidase (GPX) in the liver tissue and mitochondria than the HS group, and the same pattern was observed for glutathione (GSH) and GSH/glutathione disulphide (GSSG) in the liver tissue. The decreased mRNA levels of GPX1 and uncoupling protein (UCP) in the liver induced by HS were restored by BET supplementation. In conclusion, dietary BET supplementation can alleviate HS-induced hepatic and mitochondrial oxidative damage of broilers by regulating mRNA expressions of GPX1 and UCP.
\end{abstract}

Key words: betaine, broiler, heat stress, mitochondria, redox state

J. Poult. Sci., 58: 103-109, 2021

\section{Introduction}

Heat stress (HS) is one of the major environmental concerns in broiler industry. High temperature conditions decrease the feed intake of broilers and disturb their normal physiological homeostasis. Then, the increase of cellular reactive oxygen species (ROS) levels occur, causing oxidative stress and mitochondrial dysfunction, which in turn, reduce nutrient digestibility and, finally, impair growth performance (Lara and Rostagno, 2013). Oxidative stress is defined as an imbalance between the production of ROS and its elimination caused by a depression in antioxidant systems

Received: January 11, 2020, Accepted: May 1, 2020

Released Online Advance Publication: July 25, 2020

Correspondence: Dr. Yanmin Zhou, College of Animal Science and Technology, No. 1 Weigang, Nanjing, Jiangsu 210095, China.

(E-mail: zhouym6308@163.com)

${ }^{1}$ Both authors contributed equally to this work.

The Journal of Poultry Science is an Open Access journal distributed under the Creative Commons Attribution-NonCommercial-ShareAlike 4.0 International License. To view the details of this license, please visit (https:// creativecommons.org/licenses/by-nc-sa/4.0/).
(Lin et al., 2006). It was demonstrated that HS reduced the activity of antioxidant enzymes including superoxide dismutase (SOD) and glutathione peroxidase (GPX) and the contents of glutathione (GSH), and increased lipid peroxidation reflected by malondialdehyde (MDA) content (Yang et al., 2010; Del Vesco et al., 2017).

The mitochondrial respiratory chain is the major site of ROS formation, and previous studies have revealed that increased ROS production in heat-treated broilers is associated with mitochondrial damage, such as a reduced antioxidant activity and the downregulation of uncoupling protein (UCP) (Huang et al., 2015). As a protein found in the inner mitochondrial membrane, UCP is related to heat production, and this uncoupling mechanism in ATP production enables a reduction of the production of ROS (Abe et al., 2006).

Several nutritional strategies have been proposed for alleviating the negative effects of HS in broilers, in which betaine (BET) has received increasing attention (Ratriyanto and Mosenthin, 2018). The principal physiologic role of betaine is as an osmolyte and methyl donor (transmethylation). As an osmolyte, BET protects cells, proteins, and enzymes 
from environmental stress. As a methyl donor, BET is involved in the transfer of methyl groups via the methionine cycle in vital biological processes (Kidd et al., 1997). The methyl group of BET can be transferred to homocysteine via betainehomocysteine methyltransferase to yield methionine; thus, BET is expected to replace the expensive synthetic methionine to reduce the feed cost (Eklund et al., 2005). It has been shown that BET can be used to spare about $25 \%$ of the total methionine in broiler diets without affecting growth performance (Sun et al., 2008), but excessive replacement may decrease meat quality and some muscle amino acid contents (Fu et al., 2016).

Administration of betaine has been shown to exert cellular and subcellular membrane stabilization by restoring both non-enzymic and enzymic antioxidants, and acts as a positive regulator of mitochondrial function (Lee, 2015). Dietary BET supplementation was found to reduce the negative impact of HS on growth performance of broilers (He et al., 2015). However, whether BET alleviates HS by regulating antioxidant systems in tissues and mitochondria of broilers has not been fully elucidated. Therefore, the present study was conducted to evaluate the effects of dietary BET on growth performance, antioxidant activity, and mRNA expression of related genes in the liver tissue and mitochondria of broiler exposed to HS.

\section{Materials and Methods}

\section{Experimental Design, Diets, and Animal Husbandry}

All experimental procedures involving animals were approved by Nanjing Agricultural University Institutional Animal Care and Use Committee.

A total of 144 21-day-old male broiler chickens with similar body weight (BW) were assigned randomly to 3 treatments with 6 replicates of 8 chickens per replicate cage (110 $\mathrm{cm} \times 60 \mathrm{~cm} \times 50 \mathrm{~cm})$. Broilers in the control $(\mathrm{CON})$ group were kept at thermoneutral $\left(\mathrm{TN}, 22 \pm 1^{\circ} \mathrm{C}\right)$ conditions and fed a basal diet until they were 42 days of age. Broilers in the other two groups (defined as HS and HS + BET) were exposed to $\mathrm{HS}\left(34 \pm 1^{\circ} \mathrm{C}\right.$ for $8 \mathrm{~h}$ from 9:00 to 17:00 and $22 \pm$ $1{ }^{\circ} \mathrm{C}$ the rest of time) and fed the basal diet without or with $1000 \mathrm{mg} / \mathrm{kg}$ BET (96\% anhydrous, Skystone Feed Co., Ltd, Yixing, China). The betaine concentration was selected according to our previous study (Chen et al., 2018). Ingredient composition and calculated nutrient content of the basal diet are presented in Table 1. Broilers were allowed free access to mash feed and water with a 18L:6D lighting program. The number of birds that died during the study was recorded.

\section{Sample Collection}

At 22,32 , and 42 days of age, the rectal and cockscomb temperature was determined at 13:00 by using a rectal thermometer and a Fluke TiR1 Thermal Imager, as previously described (Giloh et al., 2012). At 42 days of age, all broilers were weighed in replicates after feed deprivation for $12 \mathrm{~h}$ and feed intake was recorded to calculate the average daily gain (ADG), average daily feed intake (ADFI), and feed conversion ratio (FCR). Then, one broiler from each replicate was randomly selected. Blood samples (about $5 \mathrm{~mL}$ each) were
Table 1. Ingredient composition and nutrient content of the basal diet (g/kg, unless otherwise stated)

\begin{tabular}{lc}
\hline \multicolumn{1}{c}{ Items } & $21-42$ days \\
\hline Ingredient & \\
Corn & 619 \\
Soybean meal & 256 \\
Corn gluten meal & 43 \\
Soybean oil & 38 \\
Dicalcium phosphate & 16 \\
Limestone & 12 \\
L-Lysine, HCl & 2 \\
DL-Methionine & 1 \\
Sodium chloride & 3 \\
Choline chloride & 0.6 \\
Vitamin and mineral mix ${ }^{1}$ & 9.4 \\
Nutrient content & \\
Metabolizable energy (MJ/kg) & 13.10 \\
Crude protein & 197.10 \\
Digestible lysine & 9.58 \\
Digestible methionine & 4.08 \\
Digestible methionine + cystine & 7.05 \\
Digestible isoleucine & 7.10 \\
Digestible threonine & 6.94 \\
Digestible valine & 8.02 \\
Digestible tryptophan & 1.85 \\
Calcium & 9.00 \\
Available phosphorus & 4.20 \\
\hline The premix provided & \\
\hline
\end{tabular}

\footnotetext{
${ }^{1}$ The premix provided per kilogram of diet: vitamin A (transretinyl acetate), 10,000 IU; vitamin $\mathrm{D}_{3}$ (cholecalciferol), 3,000 IU; vitamin E (all-rac- $\alpha$-tocopherol acetate), $30 \mathrm{IU}$; menadione, $1.3 \mathrm{mg}$; thiamin, $2.2 \mathrm{mg}$; riboflavin, $8 \mathrm{mg}$; nicotinamide, $40 \mathrm{mg}$; calcium pantothenate, $10 \mathrm{mg}$; pyridoxine $\cdot \mathrm{HCl}, 4 \mathrm{mg}$; biotin, $0.04 \mathrm{mg}$; folic acid, $1 \mathrm{mg}$; vitamin $\mathrm{B}_{12}$ (cobalamin), $0.013 \mathrm{mg}$; Fe (from ferrous sulfate), $80 \mathrm{mg}$; $\mathrm{Cu}$ (from copper sulfate), $8 \mathrm{mg}$; Mn (from manganese sulfate), $110 \mathrm{mg}$; Zn (from zinc oxide), $65 \mathrm{mg}$; I (from calcium iodate), $1.1 \mathrm{mg}$; and Se (from sodium selenite), $0.3 \mathrm{mg}$.
}

taken from wing vein and centrifuged at $3,000 \times g$ for $15 \mathrm{~min}$ at $4^{\circ} \mathrm{C}$ to separate the serum, which was frozen at $-20^{\circ} \mathrm{C}$ for further analysis. After blood collection, birds were killed by cervical dislocation. The liver was collected and divided into two parts: one part was immediately processed to isolate mitochondria and the other part was stored in liquid nitrogen until analysis.

\section{Isolation of Liver Mitochondria}

Liver mitochondria were isolated according to the previously described method (Zhang et al., 2015). Briefly, the fresh liver samples were mechanically homogenized with a Bio-Gen PRO 200 homogenizer (Pro Scientific, Inc.,Oxford, $\mathrm{UK})$ in an ice-cold isolation buffer $(\mathrm{pH}=7.4$, containing 10 $\mathrm{mM}$ Trizma hydrochloride, $250 \mathrm{mM}$ sucrose, and $1 \mathrm{mM}$ EDTA) and centrifuged at $800 \times g$ for $5 \mathrm{~min}$ at $4^{\circ} \mathrm{C}$. The supernatant was centrifuged at $12,000 \times g$ for $15 \mathrm{~min}$ at $4^{\circ} \mathrm{C}$ to obtain the mitochondrial pellet. Then, the pellet was washed twice with the isolation buffer and resuspended in the ice-cold isolation buffer, and finally stored at $-80^{\circ} \mathrm{C}$ until analysis. 


\section{Measurement of Serum Aminotransferase Activities}

Serum aspartate aminotransferase (AST) and alanine aminotransferase (ALT) activities were measured using commercial kits (Nanjing Jiancheng Bioengineering Institute, Nanjing, China) according to the manufacturer's instructions.

\section{Determination of Antioxidant Activity}

The homogenate of liver tissue was prepared as previously described (Wen et al., 2017). The activities of SOD, glutathione peroxidase (GPX), glutathione reductase (GR), GSH, and glutathione disulphide (GSSG), and the malondialdehyde (MDA) concentration in the liver tissue and mitochondria were determined using commercial kits (Nanjing Jiancheng Bioengineering Institute). The protein concentration of the liver homogenate and mitochondrial suspension was determined using the bicinchoninic acid assay (Bainor et al., 2011).

\section{Messenger RNA Quantification}

Total RNA was isolated from the liver tissue using RNAiso Reagent (TaKaRa Bio, Shiga, Japan) and diluted in diethyl pyrocarbonate treated water to an appropriate concentration, as previously described (Wen et al., 2012). Then, reverse transcription of total RNA was completed using PrimeScript RT Reagent Kit (TaKaRa), and the cDNA was quantified using SYBR Premix Ex Taq II Kit (TaKaRa) on ABI 7300 Real-Time PCR System (Applied Biosystems, Foster City, CA). Optimized cycling conditions of all genes were $95^{\circ} \mathrm{C}$ for $30 \mathrm{~s}$, followed by 40 cycles of $95^{\circ} \mathrm{C}$ for $5 \mathrm{~s}$, $60^{\circ} \mathrm{C}$ for $31 \mathrm{~s}$, and a final dissociation stage of $95^{\circ} \mathrm{C}$ for $15 \mathrm{~s}$, $60^{\circ} \mathrm{C}$ for $1 \mathrm{~min}, 95^{\circ} \mathrm{C}$ for $15 \mathrm{~s}$, and $60^{\circ} \mathrm{C}$ for $15 \mathrm{~s}$. The sequences of primers for the genes tested (SOD1, GPX1, and UCP) were specifically designed according to the sequences located in GenBank (Table 2). The geometric means of glyceraldehyde 3-phosphate dehydrogenase (GAPDH) and $\beta$-actin were used to normalize the genes of interest, as recommended (Vandesompele et al., 2002). Relative mRNA levels (arbitrary units) were calculated on the basis of PCR efficiency and threshold cycle values, as previously described (Pfaffl, 2001). The mRNA level of each target gene for the CON group was assigned the value of one.

\section{Statistical Analysis}

All data were analyzed by one-way ANOVA using SPSS statistical software (version 22.0 for Windows, SPSS Inc., Chicago, IL). Differences among treatments were examined by Duncan's multiple range test, which were considered significant at a $P<0.05$. Data are presented as means and standard error of means (SEM).

\section{Results}

\section{Rectal and Cockscomb Temperature}

Compared with the CON group, rectal and cockscomb temperatures were increased $(P<0.05)$ in HS and HS + BET groups at all days tested, but there was no difference between HS and HS + BET groups (Table 3).

\section{Growth Performance}

Mortality was low (3.1\% in total) and did not differ among groups (data not shown). The HS group had a lower $(P<$ 0.05 ) final $\mathrm{BW}, \mathrm{ADG}$, and ADFI than the CON group, but there was no significant difference in FCR (Table 4). The $\mathrm{HS}+\mathrm{BET}$ group resulted in a higher $(P<0.05)$ final $\mathrm{BW}$, ADG, and ADFI than the HS group, but did not affect the FCR.

\section{Serum Aminotransferase Activities}

The HS group had greater $(P<0.05)$ activities of AST and ALT in serum than the CON group (Table 5). Betaine supplementation decreased $(P<0.05)$ serum ALT activity in broilers exposed to HS, whereas this effect was not observed for AST.

\section{Redox State in the Liver Tissue and Mitochondria}

Compared with the CON group, the HS group increased $(P$ $<0.05)$ MDA content and decreased $(P<0.05)$ SOD activity in the liver tissue and mitochondria (Table 6). Additionally, GSH content and GSH/GSSG of the HS group were decreased in the liver tissue $(P<0.05)$. Compared with the HS group, the HS + BET group had increased $(P<0.05)$ SOD and GPX activities in the liver tissue and mitochondria, and increased GSH content and GSH/GSSG ratio, and decreased MDA content in the liver tissue.

\section{Gene Expression}

Compared with the CON group, the HS group had lower $(P<0.05)$ mRNA levels of GPX1 and UCP in the liver, which were restored $(P<0.05)$ in the HS + BET group to the CON levels (Table 7). There was no difference in SOD1

Table 2. Sequences for real-time PCR primers

\begin{tabular}{|c|c|c|c|}
\hline Gene $^{1}$ & GeneBank ID & Primer sequence, sense/antisense & Product size, bp \\
\hline \multirow[t]{2}{*}{ SOD1 } & NM_205064.1 & AGGAGTGGCAGAAGTAGAAA & 157 \\
\hline & & TAAACGAGGTCCAGCAT & \\
\hline \multirow[t]{2}{*}{ GPX1 } & NM_001277853.1 & GCCCGCACCTCTGTCATAC & 157 \\
\hline & & TGCTTCTCCAGGCTGTTCC & \\
\hline \multirow[t]{2}{*}{ UCP } & AB088685.1 & GAGAAACAGAGCGGGATTTGAT & 90 \\
\hline & & GCTCCTGGCTCACGGATAGA & \\
\hline \multirow[t]{2}{*}{$\beta$-actin } & NM_205518 & TGCTGTGTTCCCATCTATCG & 150 \\
\hline & & TTGGTGACAATACCGTGTTCA & \\
\hline \multirow[t]{2}{*}{ GAPDH } & NM_204305 & AGAACATCATCCCAGCGTCC & 133 \\
\hline & & CGGCAGGTCAGGTCAACAAC & \\
\hline
\end{tabular}

\footnotetext{
${ }^{1}$ SOD1, superoxide dismutase 1; GPX1, glutathione peroxidase; UCP, uncoupling protein; GAPDH, glyceraldehyde 3-phosphate dehydrogenase.
} 
Table 3. Effect of betaine on rectal and cockscomb temperature of heat-stressed broilers at different ages

\begin{tabular}{lccccc}
\hline \hline \multicolumn{1}{c}{ Item $^{1}$} & CON & HS & HS + BET & SEM & $P$ value \\
\hline Rectal temperature $\left({ }^{\circ} \mathrm{C}\right)$ & & & & & \\
$22 \mathrm{~d}$ & $41.1^{\mathrm{b}}$ & $41.7^{\mathrm{a}}$ & $41.6^{\mathrm{a}}$ & 0.11 & 0.028 \\
$32 \mathrm{~d}$ & $41.3^{\mathrm{b}}$ & $42.5^{\mathrm{a}}$ & $42.6^{\mathrm{a}}$ & 0.16 & 0.001 \\
$42 \mathrm{~d}$ & $41.3^{\mathrm{b}}$ & $42.1^{\mathrm{a}}$ & $42.1^{\mathrm{a}}$ & 0.08 & 0.003 \\
Cockscomb temperature $\left({ }^{\circ} \mathrm{C}\right)$ & & & & & \\
$22 \mathrm{~d}$ & $34.7^{\mathrm{b}}$ & $36.5^{\mathrm{a}}$ & $36.9^{\mathrm{a}}$ & 0.34 & 0.005 \\
$32 \mathrm{~d}$ & $34.7^{\mathrm{b}}$ & $36.3^{\mathrm{a}}$ & $37.2^{\mathrm{a}}$ & 0.35 & 0.002 \\
$42 \mathrm{~d}$ & $34.9^{\mathrm{b}}$ & $36.5^{\mathrm{a}}$ & $37.4^{\mathrm{a}}$ & 0.37 & 0.002 \\
\hline
\end{tabular}

${ }^{1} \mathrm{CON}$, broilers were kept at thermoneutral $\left(22 \pm 1^{\circ} \mathrm{C}\right)$ conditions and fed a basal diet. HS, broilers were exposed to HS $\left(34 \pm 1^{\circ} \mathrm{C}, 8 \mathrm{~h} /\right.$ day) conditions and fed a basal diet. HS + BET, broilers were exposed to HS $\left(34 \pm 1^{\circ} \mathrm{C}, 8 \mathrm{~h} /\right.$ day) conditions and fed a basal diet supplemented with $1000 \mathrm{mg} / \mathrm{kg}$ betaine. SEM, standard error of means $(n=6)$.

${ }^{\text {a, b }}$ Means within a row with different superscripts differ significantly at $P<0.05$. The $P$ value is the significance level for analysis of variance $F$ test among all groups.

Table 4. Effect of betaine on growth performance of heat-stressed broilers from 21 to 42 days of age

\begin{tabular}{lrrrrr}
\hline \multicolumn{1}{c}{ Item $^{1,2}$} & \multicolumn{1}{c}{ CON } & \multicolumn{1}{c}{ HS } & HS + BET & SEM & $P$ value \\
\hline Initial BW & 736.70 & 714.50 & 711.15 & 8.37 & 0.430 \\
Final BW & $2311.17^{\mathrm{a}}$ & $2141.46^{\mathrm{b}}$ & $2219.09^{\mathrm{a}}$ & 23.83 & 0.004 \\
ADG (g/day) & $74.97^{\mathrm{a}}$ & $67.95^{\mathrm{b}}$ & $71.81^{\mathrm{a}}$ & 1.01 & 0.006 \\
ADFI (g/day) & $140.98^{\mathrm{a}}$ & $126.28^{\mathrm{b}}$ & $137.31^{\mathrm{a}}$ & 2.48 & 0.027 \\
FCR & 1.88 & 1.86 & 1.91 & 0.02 & 0.493 \\
\hline
\end{tabular}

${ }^{1} \mathrm{CON}$, broilers were kept at thermoneutral $\left(22 \pm 1^{\circ} \mathrm{C}\right)$ conditions and fed a basal diet. HS, broilers were exposed to $\mathrm{HS}\left(34 \pm 1^{\circ} \mathrm{C}, 8 \mathrm{~h} /\right.$ day) conditions and fed a basal diet. $\mathrm{HS}+\mathrm{BET}$, broilers were exposed to HS $\left(34 \pm 1^{\circ} \mathrm{C}, 8 \mathrm{~h} /\right.$ day) conditions and fed a basal diet supplemented with $1000 \mathrm{mg} / \mathrm{kg}$ betaine. SEM, standard error of means $(n=6)$.

${ }^{2} \mathrm{BW}$, body weight; ADG, average daily gain; ADFI, average daily feed intake; FCR, feed conversion ratio.

${ }^{\mathrm{a}, \mathrm{b}}$ Means within a row with different superscripts differ significantly at $P<0.05$. The $P$ value is the significance level for analysis of variance $F$ test among all groups.

Table 5. Effect of betaine on serum aminotransferase activities of heat-stressed broilers

\begin{tabular}{crrrrc}
\hline \hline Item $^{1,2}$ & CON & HS & HS + BET & SEM & $P$ value \\
\hline AST $(\mathrm{U} / \mathrm{mL})$ & $35.35^{\mathrm{b}}$ & $58.76^{\mathrm{a}}$ & $57.79^{\mathrm{a}}$ & 4.04 & 0.005 \\
ALT $(\mathrm{U} / \mathrm{mL})$ & $7.46^{\mathrm{b}}$ & $8.36^{\mathrm{a}}$ & $7.59^{\mathrm{b}}$ & 0.14 & 0.006 \\
\hline
\end{tabular}

${ }^{1} \mathrm{CON}$, broilers were kept at thermoneutral $\left(22 \pm 1^{\circ} \mathrm{C}\right)$ conditions and fed a basal diet. HS, broilers were exposed to $\mathrm{HS}\left(34 \pm 1^{\circ} \mathrm{C}, 8 \mathrm{~h} /\right.$ day $)$ conditions and fed a basal diet. $\mathrm{HS}+\mathrm{BET}$, broilers were exposed to HS ( $34 \pm 1{ }^{\circ} \mathrm{C}, 8 \mathrm{~h} /$ day) conditions and fed a basal diet supplemented with $1000 \mathrm{mg} / \mathrm{kg}$ betaine. SEM, standard error of means $(n=6)$.

${ }^{2}$ AST, aspartate aminotransferase; ALT, alanine aminotransferase.

${ }^{\mathrm{a}, \mathrm{b}}$ Means within a row with different superscripts differ significantly at $P<0.05$. The $P$ value is the significance level for analysis of variance $F$ test among all groups.

mRNA expression among groups.

\section{Discussion}

Our data showed that the HS increased rectal and cockscomb temperature and decreased ADG and ADFI compared with the CON group, which was in accordance with previous research (Azad et al., 2010). Although BET supplementation did not affect body temperature, it resulted in higher ADG and ADFI than the HS group, which was consistent to the results of previous studies (He et al., 2015; AkhavanSalamat and Ghasemi, 2016). The positive effects of BET on growth performance of broilers under HS might be partly 
Wen et al.: Betaine and Broilers under Heat Stress

Table 6. Effect of betaine on redox state of the liver tissue and mitochondria in heatstressed broilers

\begin{tabular}{lccccc}
\hline \hline \multicolumn{1}{c}{ Item ${ }^{1,2}$} & CON & HS & HS + BET & SEM & $P$ value \\
\hline Liver tissue & & & & & \\
MDA (nmol/mg prot) & $3.04^{\mathrm{b}}$ & $4.67^{\mathrm{a}}$ & $3.34^{\mathrm{b}}$ & 0.27 & 0.016 \\
SOD (U/mg prot) & $48.27^{\mathrm{a}}$ & $40.10^{\mathrm{b}}$ & $47.04^{\mathrm{a}}$ & 1.39 & 0.033 \\
GPX (U/mg prot) & $49.90^{\mathrm{ab}}$ & $43.07^{\mathrm{b}}$ & $56.90^{\mathrm{a}}$ & 3.07 & 0.036 \\
GR (U/mg prot) & 8.06 & 7.73 & 7.67 & 0.45 & 0.940 \\
GSH (mg/g prot) & $9.56^{\mathrm{a}}$ & $7.81^{\mathrm{b}}$ & $9.14^{\mathrm{a}}$ & 0.32 & 0.035 \\
GSSG (mg/g prot) & 1.79 & 2.03 & 1.93 & 0.13 & 0.777 \\
GSH/GSSG ratio & $5.25^{\mathrm{a}}$ & $3.90^{\mathrm{b}}$ & $4.88^{\mathrm{a}}$ & 0.37 & 0.025 \\
Mitochondria & & & & & \\
MDA (nmol/mg prot) & $2.24^{\mathrm{b}}$ & $3.72^{\mathrm{a}}$ & $3.08^{\mathrm{ab}}$ & 0.24 & 0.036 \\
SOD (U/mg prot) & $35.64^{\mathrm{a}}$ & $28.37^{\mathrm{b}}$ & $35.27^{\mathrm{a}}$ & 1.42 & 0.032 \\
GPX (U/mg prot) & $31.10^{\mathrm{ab}}$ & $25.09^{\mathrm{b}}$ & $42.04^{\mathrm{a}}$ & 3.69 & 0.003 \\
GR (U/mg prot) & 3.07 & 3.26 & 2.54 & 0.18 & 0.334 \\
GSH (mg/g prot) & 3.73 & 3.82 & 3.61 & 0.29 & 0.996 \\
GSSG (mg/g prot) & 1.65 & 1.54 & 1.46 & 0.11 & 0.777 \\
GSH/GSSG ratio & 2.5 & 3.3 & 2.9 & 0.08 & 0.545 \\
\hline
\end{tabular}

${ }^{1} \mathrm{CON}$, broilers were kept at thermoneutral $\left(22 \pm 1{ }^{\circ} \mathrm{C}\right)$ conditions and fed a basal diet. HS, broilers were exposed to HS $\left(34 \pm 1^{\circ} \mathrm{C}, 8 \mathrm{~h} /\right.$ day) conditions and fed a basal diet. HS + BET, broilers were exposed to HS $\left(34 \pm 1^{\circ} \mathrm{C}, 8 \mathrm{~h} /\right.$ day) conditions and fed a basal diet supplemented with $1000 \mathrm{mg} / \mathrm{kg}$ betaine. SEM, standard error of means $(n=6)$.

${ }^{2}$ MDA, malondialdehyde; SOD, superoxide dismutase; GPX, glutathione peroxidase; GR, glutathione reductase; GSH, glutathione; GSSG, glutathione disulphide.

${ }^{\mathrm{a}, \mathrm{b}}$ Means within a row with different superscripts differ significantly at $P<0.05$. The $P$ value is the significance level for analysis of variance $F$ test among all groups.

Table 7. Effect of betaine on hepatic gene expression in heat-stressed broilers

\begin{tabular}{lllccc}
\hline \hline Item $^{1,2}$ & CON & HS & HS + BET & SEM & $P$ value \\
\hline SOD1 & 1.00 & 1.11 & 1.51 & 0.10 & 0.089 \\
GPX1 & $1.00^{\mathrm{a}}$ & $0.75^{\mathrm{b}}$ & $1.08^{\mathrm{a}}$ & 0.04 & 0.001 \\
UCP & $1.00^{\mathrm{a}}$ & $0.71^{\mathrm{b}}$ & $0.92^{\mathrm{a}}$ & 0.05 & 0.014 \\
\hline
\end{tabular}

${ }^{1} \mathrm{CON}$, broilers were kept at thermoneutral $\left(22 \pm 1{ }^{\circ} \mathrm{C}\right)$ conditions and fed a basal diet. HS, broilers were exposed to $\mathrm{HS}\left(34 \pm 1^{\circ} \mathrm{C}, 8 \mathrm{~h} /\right.$ day $)$ conditions and fed a basal diet. $\mathrm{HS}+\mathrm{BET}$, broilers were exposed to $\mathrm{HS}\left(34 \pm 1^{\circ} \mathrm{C}, 8 \mathrm{~h} /\right.$ day) conditions and fed a basal diet supplemented with $1000 \mathrm{mg} / \mathrm{kg}$ betaine. SEM, standard error of means $(n=6)$.

${ }^{2}$ SOD1, superoxide dismutase 1; GPX1, glutathione peroxidase 1; UCP, uncoupling protein.

${ }^{\mathrm{a}, \mathrm{b}}$ Means within a row with different superscripts differ significantly at $P<0.05$. The $P$ value is the significance level for analysis of variance $F$ test among all groups.

attributed to the osmoregulatory property of BET to the maintenance of protein structure, enzyme, and cell function, irrespective of its role as a methyl group donor (Craig, 2004). In addition, BET might alleviate fear response of broilers under HS by inhibiting oxidative stress, thus increasing the feed take of broilers (Ratriyanto and Mosenthin, 2018). It was reported that administration of betaine to drinking water decreased the tonic immobility in broiler chickens during the hot-dry season, which was associated with increased activities of SOD and GPX in serum (Egbuniwe et al., 2016). However, the improved FCR by dietary BET described in the reports above was not observed in our study. The discrepancy may be due to exposure period, temperature, genotype, and age of broilers (Attia et al., 2009).

As markers of hepatic damage, serum ALT and AST activities were higher in HS group than in CON group, agreeing with the previous data (Tang et al., 2013). This is attributed to cellular leakage and loss of the functional integrity of hepatic cell membrane induced by HS, resulting in the release of ALT and AST from the cytoplasm (Lin et al., 2006). The ALT activity in broilers under HS was reduced by BET supplementation, which was consistent with the previous data (Konca et al., 2008), suggesting that BET could alleviate HS-induced hepatic damage. This can be explained by the effect of BET in maintaining the structural and functional integrity of cell membranes (Ganesan et al., 
2010). No difference in serum AST activity in broilers under HS implied that it may be less responsive to BET supplementation. However, dietary BET was reported to decrease only serum AST activity in rabbits under high ambient temperature (Hassan et al., 2011), whereas there was no effect of BET on the activities of these two enzymes in growing pigs during HS condition (Mendoza et al., 2017), implying that the effect of BET may vary in different animal species.

Increased MDA content and decreased SOD activity in the liver tissue and mitochondria as well as decreased GSH content and GSH/GSSG in the liver tissue were observed in the HS group, supporting the view that oxidative stress is part of the stress response of broilers to heat exposure (Lin et al., 2006; Yang et al., 2010). The alteration of SOD activity and contents of GSH and MDA was reversed by BET supplementation, which also increased GPX activity. Our findings demonstrated that BET alleviated oxidative stress of the liver induced by HS, which might contribute to improved ADG and ADFI of broilers. Similar results were obtained by Akhavan-Salamat and Ghasemi (2016), who reported that BET supplementation increased SOD and GPX activities and reduced MDA concentration in serum of broilers under HS. Betaine may have antioxidant effects against oxidative damage by restoring S-adenosylmethionine, which contributes to an enhancement in the supply of substrate needed for the synthesis of GSH that protects the cell from ROS (Alirezaei et al., 2012). The increased GPX activity may be explained by the larger amount of GSH available with BET supplementation that enables the GSH antioxidant system to operate adequately.

Compared with the CON group, HS group reduced GPX1 and UCP mRNA levels in the liver. Previous reports have shown that HS stimulated ROS production possibly by downregulating UCP mRNA and protein levels (Mujahid et al., 2006; Del Vesco et al., 2015), and the increase of hydrogen peroxide production downregulated GPX1 gene expression (Habashy et al., 2018). Dietary BET supplementation increased mRNA expression of GPX1 and UCP genes in the liver of broilers under HS, which may contribute to the alleviation of oxidative damage induced by HS. This may be due to the methionine-sparing effect of BET, allowing more methionine to be utilized to increase the expression levels of genes related to antioxidant activity (Del Vesco et al., 2015). The increase of UCP mRNA expression may also be related to the positive effect of BET on mitochondrial respiration (Lee, 2015). As avian UCP is mainly expressed in the skeletal muscle (Dridi et al., 2004), further investigations are required to assess the role of hepatic UCP gene expression in response to HS and betaine supplementation.

In conclusion, this study indicated that dietary BET supplementation slightly alleviated the HS-induced growth repression and hepatic injury, and improved antioxidant activity in the liver tissue and mitochondria of broilers possibly by increasing the activities of SOD and GPX and GSH content, and by upregulating the transcription of GPX1 and UCP genes.

\section{Acknowledgment}

This study was supported by grants from Cooperative Innovation Foundation of Industry - Prospective Joint Research Projects of Jiangsu Province (BY2014128-03). The authors wish to thank their lab mates for assistance.

\section{Conflicts of Interest}

The authors declare no conflicts of interest.

\section{References}

Abe T, Mujahid A, Sato K, Akiba Y and Toyomizu M. Possible role of avian uncoupling protein in down-regulating mitochondrial superoxide production in skeletal muscle of fasted chickens. FEBS Letters, 580: 4815-4822. 2006.

Akhavan-Salamat $\mathrm{H}$ and Ghasemi HA. Alleviation of chronic heat stress in broilers by dietary supplementation of betaine and turmeric rhizome powder: dynamics of performance, leukocyte profile, humoral immunity, and antioxidant status. Tropical Animal Health and Production, 48: 181-188. 2016.

Alirezaei M, Jelodar G and Ghayemi Z. Antioxidant defense of betaine against oxidative stress induced by ethanol in the rat testes. International Journal of Peptide Research and Therapeutics, 18: 239-247. 2012.

Attia YA, Hassan RA and Qota EMA. Recovery from adverse effects of heat stress on slow-growing chicks in the tropics 1 : Effect of ascorbic acid and different levels of betaine. Tropical Animal Health and Production, 41: 807-818. 2009.

Azad KMA, Kikusato M, Hoque AM and Toyomizu M. Effect of chronic heat stress on performance and oxidative damage in different strains of chickens. Journal of Poultry Science, 47: 333-337. 2010.

Bainor A, Chang L, Mcquade TJ, Webb B and Gestwicki JE. Bicinchoninic acid (BCA) assay in low volume. Analytical Biochemistry, 410: 310-312. 2011.

Chen R, Zhuang S, Chen YP, Cheng YF, Wen C and Zhou YM. Betaine improves the growth performance and muscle growth of partridge shank broiler chickens via altering myogenic gene expression and insulin-like growth factor-1 signaling pathway. Poultry Science, 97: 4297-4305. 2018.

Craig SA. Betaine in human nutrition. American Journal of Clinical Nutrition, 80: 539-549. 2004.

Del Vesco AP, Gasparino E, Grieser DdO, Zancanela V, Soares MAM and de Oliveira Neto AR. Effects of methionine supplementation on the expression of oxidative stress-related genes in acute heat stress-exposed broilers. British Journal of Nutrition, 113: 549-559. 2015.

Del Vesco AP, Khatlab AS, Goes ESR, Utsunomiya KS, Vieira JS, Oliveira Neto AR and Gasparino E. Age-related oxidative stress and antioxidant capacity in heat-stressed broilers. Animal, 11: 1783-1790. 2017.

Dridi S, Onagbesan O, Swennen Q, Buyse J, Decuypere E and Taouis M. Gene expression, tissue distribution and potential physiological role of uncoupling protein in avian species. Comparative Biochemistry and Physiology Part A: Molecular \& Integrative Physiology, 139: 273-283. 2004.

Egbuniwe IC, Ayo JO, Kawu MU and Mohammed A. Effects of betaine and ascorbic acid on tonic immobility, superoxide dismutase and glutathione peroxidase in broiler chickens during the hot-dry season. Journal of Veterinary Behavior, 12: 60-65. 2016. 
Eklund M, Bauer E, Wamatu J and Mosenthin R. Potential nutritional and physiological functions of betaine in livestock. Nutrition Research Reviews, 18: 31-48. 2005.

Fu Q, Leng ZX, Ding LR, Wang T, Wen C and Zhou YM. Complete replacement of supplemental DL-methionine by betaine affects meat quality and amino acid contents in broilers. Animal Feed Science and Technology, 212: 63-69. 2016.

Ganesan B, Buddhan S, Anandan R, Sivakumar R and Anbinezhilan R. Antioxidant defense of betaine against isoprenaline-induced myocardial infarction in rats. Molecular Biology Reports, 37: 1319-1327. 2010

Giloh M, Shinder D and Yahav S. Skin surface temperature of broiler chickens is correlated to body core temperature and is indicative of their thermoregulatory status. Poultry Science, 91: 175-188. 2012.

Habashy WS, Milfort MC, Rekaya R and Aggrey SE. Expression of genes that encode cellular oxidant/antioxidant systems are affected by heat stress. Molecular Biology Reports, 45: 389394. 2018.

Hassan RA, Ebeid TA, Abd El-Lateif AI and Ismail NB. Effect of dietary betaine supplementation on growth, carcass and immunity of New Zealand White rabbits under high ambient temperature. Livestock Science, 135: 103-109. 2011.

He S, Zhao S, Dai S, Liu D and Bokhari SG. Effects of dietary betaine on growth performance, fat deposition and serum lipids in broilers subjected to chronic heat stress. Animal Science Journal, 86: 897-903. 2015.

Huang C, Jiao H, Song Z, Zhao J, Wang X and Lin H. Heat stress impairs mitochondria functions and induces oxidative injury in broiler chickens. Journal of Animal Science, 93: 2144-2153. 2015.

Kidd MT, Ferket PR and Garlich JD. Nutritional and osmoregulatory functions of betaine. World's Poultry Science Journal, 53: 125-139. 1997.

Konca Y, Kirkpinar F, Mert S and Yaylak E. Effects of betaine on performance, carcass, bone and blood characteristics of broilers during natural summer temperatures. Journal of Animal and Veterinary Advances, 7: 930-937. 2008.

Lara LJ and Rostagno MH. Impact of heat stress on poultry production. Animals, 3: 356-369. 2013.

Lee I. Betaine is a positive regulator of mitochondrial respiration. Biochemical and Biophysical Research Communications, 456: 621-625. 2015.

Lin H, Decuypere E and Buyse J. Acute heat stress induces oxidative stress in broiler chickens. Comparative Biochemistry and Physiology Part A: Molecular \& Integrative Physiology, 144: 11-17. 2006.
Mendoza SM, Boyd RD, Ferket PR and Van HE. Effects of dietary supplementation of the osmolyte betaine on growing pig performance and serological and hematological indices during thermoneutral and heat-stressed conditions. Journal of Animal Science, 95: 5040-5053. 2017.

Mujahid A, Sato K, Akiba Y and Toyomizu M. Acute heat stress stimulates mitochondrial superoxide production in broiler skeletal muscle, possibly via downregulation of uncoupling protein content. Poultry Science, 85: 1259-1265. 2006.

Pfaffl MW. A new mathematical model for relative quantification in real-time RT-PCR. Nucleic Acids Research, 29: e45. 2001.

Ratriyanto A and Mosenthin R. Osmoregulatory function of betaine in alleviating heat stress in poultry. Journal of Animal Physiology and Animal Nutrition, 102: 1634-1650. 2018.

Sun H, Yang W, Yang Z, Wang Y, Jiang S and Zhang G. Effects of betaine supplementation to methionine deficient diet on growth performance and carcass characteristics of broilers. American Journal of Animal and Veterinary Sciences, 3: 78-84. 2008.

Tang S, Yu J, Zhang M and Bao E. Effects of different heat stress periods on various blood and meat quality parameters in young Arbor Acer broiler chickens. Canadian Journal of Animal Science, 93: 453-460. 2013.

Vandesompele J, De Preter K, Pattyn F, Poppe B, Van Roy N, De Paepe A and Speleman F. Accurate normalization of real-time quantitative RT-PCR data by geometric averaging of multiple internal control genes. Genome Biology, 3: research0034.1. 2002.

Wen C, Jiang XY, Ding LR, Wang T and Zhou YM. Effects of dietary methionine on growth performance, meat quality and oxidative status of breast muscle in fast- and slow-growing broilers. Poultry Science, 96: 1707-1714. 2017.

Wen C, Wang LC, Zhou YM, Jiang ZY and Wang T. Effect of enzyme preparation on egg production, nutrient retention, digestive enzyme activities and pancreatic enzyme messenger RNA expression of late-phase laying hens. Animal Feed Science and Technology, 172: 180-186. 2012.

Yang L, Tan GY, Fu YQ, Feng JH and Zhang MH. Effects of acute heat stress and subsequent stress removal on function of hepatic mitochondrial respiration, ROS production and lipid peroxidation in broiler chickens. Comparative Biochemistry and Physiology, Part C: Toxicology \& Pharmacology, 151: 204-208. 2010.

Zhang JF, Hu ZP, Lu CH, Yang MX, Zhang LL and Wang T. Dietary curcumin supplementation protects against heat-stressimpaired growth performance of broilers possibly through a mitochondrial pathway. Journal of Animal Science, 93: 16561665. 2015. 